Tropical Journal of Pharmaceutical Research June 2017; 16 (6): 1215-1221

ISSN: $1596-5996$ (print); 1596-9827 (electronic)

(C) Pharmacotherapy Group, Faculty of Pharmacy, University of Benin, Benin City, 300001 Nigeria.

All rights reserved.

Available online at http://www.tjpr.org

Original Research Article

http://dx.doi.org/10.4314/tjpr.v16i6.2

\title{
Effect of particle size and diluent type on critical parameters for disintegration of tablets containing croscarmellose sodium as a disintegrant
}

\author{
Prasopchai Tonglairoum, Tanasait Ngawhirunpat, Prasert Akkaramongkolporn, \\ Praneet Opanasopit and Nattawat Nattapulwat* \\ Department of Pharmaceutical Technology, Faculty of Pharmacy, Silpakorn University, Nakhon Pathom, 73000, Thailand
}

*For correspondence: Email: opanasopit_p@su.ac.th, nattapulwat_n@su.ac.th; Tel: 66-34-255800; Fax: 66-34-250941

Sent for review: 15 January 2017

Revised accepted: 17 May 2017

\begin{abstract}
Purpose: The aim of the present work was to determine the effect of particle size and type of diluents on critical concentration for the disintegration of tablet formulations containing a physical binary mixture of a superdisintegrant (croscarmellose sodium, CS) and a diluent.

Methods: The diluents used in this study were microcrystalline cellulose (MCC), dibasic calcium phosphate (DCP) and pregelatinized starch (PGS). Each diluent was divided into 2 different size ranges (small and large size)) and further mixed with 0 - $100 \%$ CS. The binary mixture was compressed at controlled pressure, and the disintegration time and physical characteristic of the tablets were evaluated.

Results: The point of CS concentration that markedly affected the disintegration time of the tablets was recorded as the critical concentration for disintegration. The results showed that the particle size of the diluent did not affect the disintegration time. The critical CS concentrations were $2 \%$ for DCP and MCC tablets and $5 \%$ for PGS tablet. Adding a small amount of CS improved the disintegration of the tablets. However, increasing the amount of CS in the formulation also affected the hardness of the tablets. The particle size of diluents had a significant effect on the critical concentration for tablet disintegration.

Conclusion: Determining the type and appropriate amounts of diluent and disintegrant (percolating component) may be useful in the design of tablet formulations.
\end{abstract}

Keywords: Disintegration, Percolation threshold, Croscarmellose sodium, Microcrystalline cellulose, Dibasic calcium phosphate, Pre-gelatinized starch

\footnotetext{
Tropical Journal of Pharmaceutical Research is indexed by Science Citation Index (SciSearch), Scopus, International Pharmaceutical Abstract, Chemical Abstracts, Embase, Index Copernicus, EBSCO, African Index Medicus, JournalSeek, Journal Citation Reports/Science Edition, Directory of Open Access Journals (DOAJ), African Journal Online, Bioline International, Open-J-Gate and Pharmacy Abstracts
}

\section{INTRODUCTION}

Drug delivery via oral route is the most preferable and convenient route of drug administration for both solid and liquid dosage forms $[1,2]$. Solid dosage forms especially tablets are widely used due to various advantages such as ease of administration, accurate dosage, self-medication, excellent physical and chemical stability, pain avoidance, and great patient compliance [3-5]. Medication tablets usually contain active pharmaceutical ingredients (APIs) and other excipients. In fact, excipients are vastly important in the development of the tablet dosage form because they have an effect on functionality and performance of tablets [6]. Various types of excipients have been employed in tablet formulations; for example, disintegrants, fillers, glidants, lubricants, etc. [7]. Among the tablet excipients, disintegrants are believed to be the essential one as they facilitate disintegration of 
the tablet into smaller pieces, and promote drug dissolution and absorption $[6,8]$.

The percolation theory scrutinizes the critical points or percolation thresholds of the system, which one ingredient of the system emerges a geometrical phase transition, creating the connection with the entire system. The formulation features such as the percentage of drug released, release rate or mechanical properties often exhibit sudden changes at the point of percolation thresholds $[9,10]$. In fact, percolation theory is on the basis of generating of clusters. A cluster can be described as a group of the neighbor-occupied point in a network [1112]. It is considered as infinite or percolating cluster after this cluster spreads from one side to the other sides of the network. The concentration of a component that causes a maximum probability of appearance of a cluster of this component is named percolation threshold [1314]. In terms of solid dosage form design, the critical concentration of disintegrant or percolation threshold of disintegrant is required to achieve the minimum disintegration time. Determination of the critical concentration of disintegrant is an important parameter for designing of a tablet formulation [15-18].

Therefore, the present study investigates the effect of size and type of diluents on critical concentration for the disintegration of tablets containing a physical binary mixture of a superdisintegrant (croscarmellose sodium) and a diluent. The critical concentration for disintegration was determined from disintegration time and disintegrant concentration profiles. MCC, DCP and PGS were used as diluents which represent different characteristics in term of water solubility and tablet deformation. Moreover, the tensile strength and hardness were also recorded in this study as a physical description and indication of the tablet quality.

\section{EXPERIMENTAL}

Microcrystalline cellulose (Avicel PH 102®; MCC) was purchased from FMC Corporation, USA. Dibasic calcium phosphate (DCP) was obtained from Budenheim, Germany. Croscarmellose sodium (CS) was purchased from CP drug center Co., Ltd., Thailand. Magnesium stearate (Mgst) was purchased from Glaxo welcome, UK. Pre-gelatinized starch (PGS) was obtained from Colorcon, USA.

\section{Diluent preparation}

In order to determine the effect of particle size of diluents on critical concentration for disintegration of tablets, the diluents (MCC, DCP) were sieved and separated into two different sizes using a vibratory sieve shaker (Haan $\mathrm{W}^{\circledR}$, Germany Model vibro Serial No. 67406). The diluents and disintegrants were kept at $50{ }^{\circ} \mathrm{C}$ in hot-air oven for $2 \mathrm{~h}$ and kept in tight container until used.

\section{Preparation of formulations}

Different binary mixtures composed of a direct compression diluent and a disintegrant were chosen as model mixtures. For each diluentdisintegrant model, different preparations with increasing disintegrant volume ratio $(0,2,5,10$, $15,20,25,30,40,50,60,70,80,90$ and $100 \%)$ were mixed for $15 \mathrm{~min}$ and stored in a dessicator with silica gel for $12 \mathrm{~h}$ prior to tableting.

\section{Preparation of tablet}

For each of binary mixture, the mixtures were directly compressed on a well-polished stainless steel punch and die assembly $(9.0 \mathrm{~mm})$ in a hydraulic press (Model SPCAC 15011) at a pressure of $5 \mathrm{kD}$ to obtain the round, flat, $9 \mathrm{~mm}$ diameter tablets.

\section{Characterization of tablets}

\section{Weight, diameter and thickness}

As a physical description and record of the tablet quality, the weight, diameter and thickness of the tablets compressed from the binary mixtures of the diluents and CS were recorded. The weight of 20 tablets corresponding to each formulation was determined using an analytical balance (Satorius $^{\circledR}$ aggottingen, Germany, Model CP224S) to assure the weight uniformity. Thickness and diameter of 10 tablets of each formulation were measured using a $25-\mathrm{mm}$ digital micrometer (Comecta, SA).

\section{Compact tensile strength}

The compact crushing strength of each formulation was determined using a Hardness tester (ERWEKA ${ }^{\circledR} \mathrm{GmbH}$, Germany, Model TBH225TD). The effect of CS in the binary mixtures on the hardness of the tablets was also determined from the hardness profiles.

\section{Disintegration time}

Disintegration studies on 6 tablets of each formulation were performed using a disintegrator (ERWEKA ${ }^{\circledR} \mathrm{GmbH}$, Germany, Model ZT323) without discs. The test was conducted in distilled water at $37 \pm 2{ }^{\circ} \mathrm{C}$. 


\section{Statistical analysis}

The data were analyzed using SPSS software. Statistical significance of differences between formulations in each experiment was examined using independent t-test. The differences were significant at $p<0.05$.

\section{RESULTS}

\section{Weight, diameter and thickness}

The weight, diameter and thickness of the tablets compressed from the binary mixtures of the diluents and CS were recorded as a physical description and record of the tablet quality (data not shown)

\section{Particle size of the diluents}

Prior to the binary-mixture preparation, the diluents (MCC, DCP and PGS) were sieved and the sizes were determined. MCC, DCP and PGS were separated into two different sizes to determine the effect of particle size of diluent on critical concentration for the disintegration of tablets. The small and larger sizes of MCC used to prepare the binary mixtures were about 112.5 and $215.0 \mu \mathrm{m}$, respectively. On the other hand, the small and larger sizes of DCP employed to prepare the binary mixtures were approximately 215.0 and $337.5 \mu \mathrm{m}$, respectively. Finally, the small and larger sizes of PGS used were recorded to be and less than 112.5 and112.5 $\mu \mathrm{m}$, respectively.

\section{Tablet disintegration}

In this study, the effect of different types and sizes of the diluents used on the disintegration time of the tablets containing CS as a disintegrant was investigated. The critical concentration for disintegration or percolation

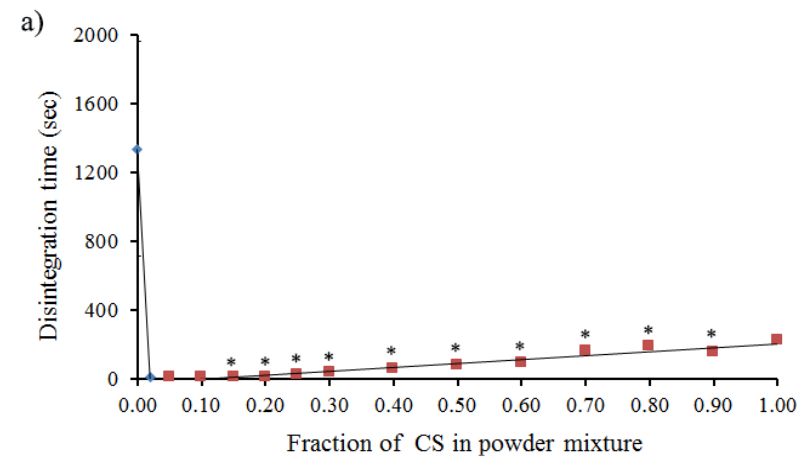

thresholds (Cp) describes the amount of disintegrant used in the tablet formulation that expresses the minimum value of the disintegration time. Figure 1 displays the relationship between the amount of CS in the binary mixture before tableting and the disintegration time of the tablets containing MCC. As it can be seen from the graph, in the case of the binary mixtures of $M C C$ and $C S$, the amount of CS used at $2 \% \mathrm{v} / \mathrm{v}$ was efficient enough to trigger a very fast disintegration. Interestingly, increasing the amount of CS in the formulations led to delay the disintegration. However, the formulations containing CS exhibited significantly lesser disintegration time as compared to the formulation without $\mathrm{CS}$. Therefore, the $\mathrm{Cp}$ of the CS in the formulations was observed to be $2 \%$ $\mathrm{v} / \mathrm{v}$. Using whether small size MCC or large size MCC offered the similar pattern of disintegration (Figure $1 \mathrm{a}$ and $\mathrm{b}$ ). The tablets containing small size MCC demonstrated significantly faster disintegration as compared with those containing big size MCC at the CS amount of $15-90 \%$.

The formulations containing DCP and CS presented the similar findings to those of MCC and CS. Figure 2 shows the relationship between the amount of CS in the binary mixture before tableting and the disintegration time of the tablets containing DCP. The percolation threshold (Cp) of the CS in the formulations was witnessed to be $2 \% \mathrm{v} / \mathrm{v}$ as well, and the amount of CS in the formulation affected the disintegration time. Increasing amount of CS resulted in the increase in disintegration time. In addition, no disintegration has been observed in the tablets containing only DCP after $1 \mathrm{~h}$. The particle sizes of DCP have a significant effect on the disintegration time (Figure 2a and Figure $2 b$ ). In the formulations with $15-20$ and $50 \%$ CS, the tablets containing small size DCP exhibited faster disintegration than those containing big size DCP. However, at the greater amount of CS

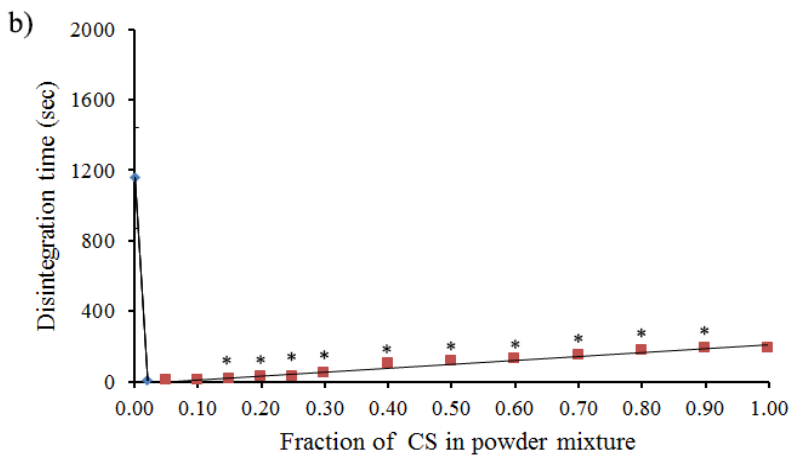

Figure 1: The relationship between the amount of CS in the binary mixture before tableting and the disintegration time of the tablets containing MCC: (a) small size MCC $(112.5 \mu \mathrm{m})(\mathrm{b})$ bigger size MCC $(215.0 \mu \mathrm{m})$. ${ }^{*}$ Statistical difference in the disintegration of tablets containing (a) small particle size MCC and (b) large particle size MCC at similar CS ratio 

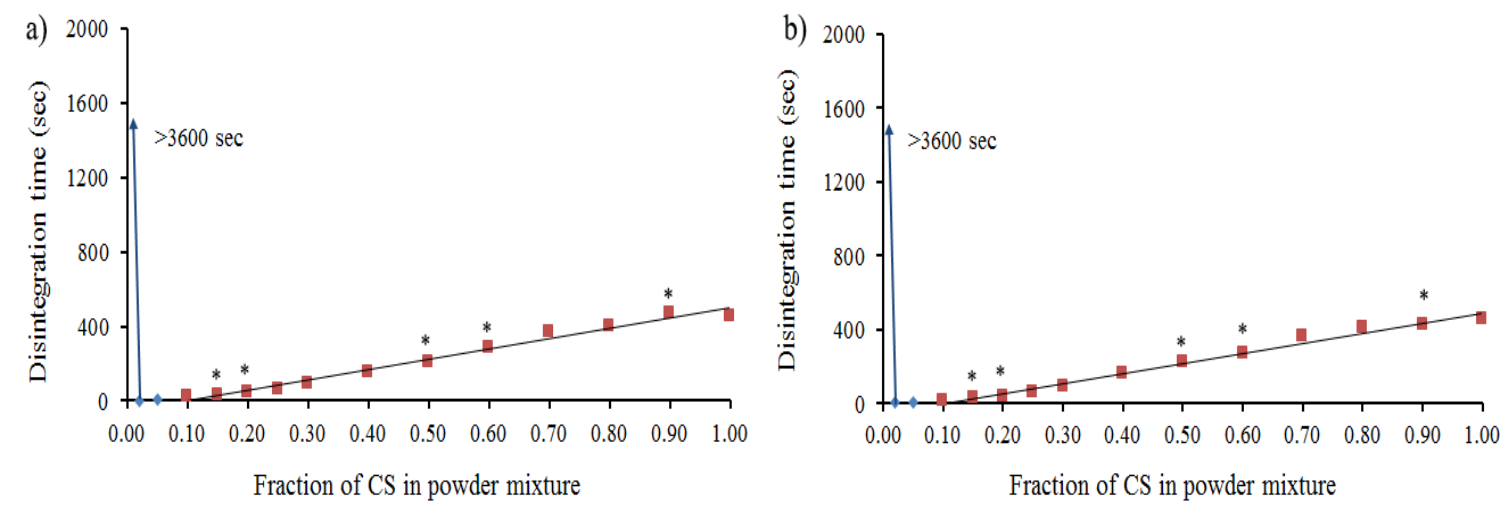

Figure 2: Relationship between the amount of CS in the binary mixture before tableting and the disintegration time of the tablets containing DCP: (a) small size DCP $(215.0 \mu \mathrm{m})(\mathrm{b})$ bigger size DCP $(337.5 \mu \mathrm{m})$. * Statistical difference in the disintegration of tablets containing (a) small particle size DCP and (b) large particle size DCP at the similar CS ratio
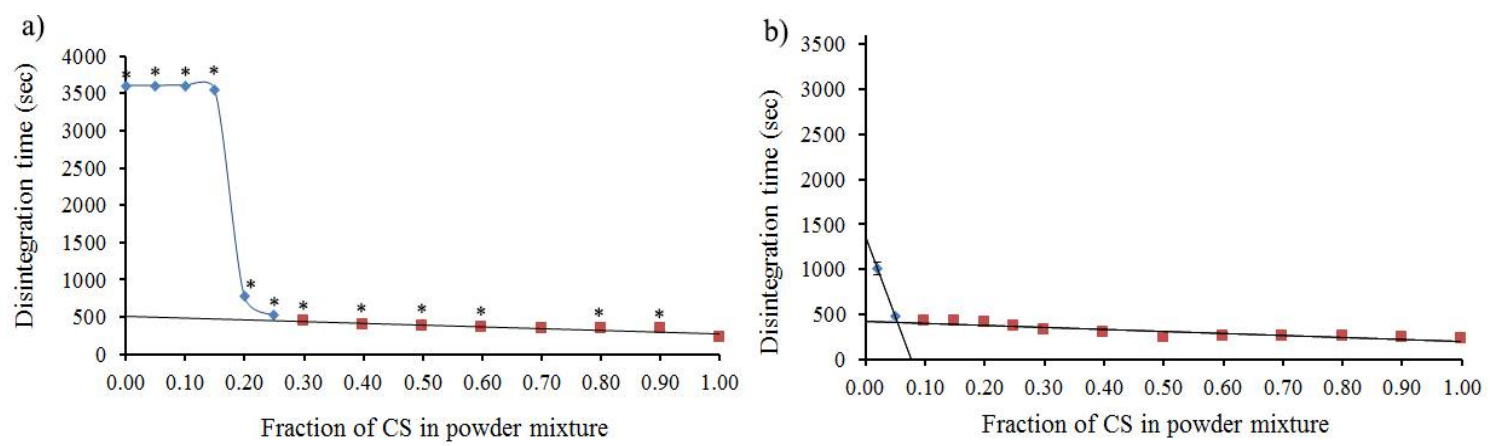

Figure 3: Relationship between the amount of CS in the binary mixture before tableting and the disintegration time of the tablets containing PGS: (a) small particle size PGS $(<112.5 \mu \mathrm{m})$ (b) larger particle size PGS $(112.5$ $\mu \mathrm{m})$. ${ }^{*}$ Statistical difference in the disintegration of tablets containing (a) small size PGS and (b) big size PGS at the similar CS ratio

$(90 \%)$ in the formulation, the tablets containing big size DCP demonstrated faster disintegration than those containing small size DCP.

The disintegration study of the formulation comprising PGS and CS was also assessed. The percolation threshold $(\mathrm{Cp})$ of the $\mathrm{CS}$ in the formulations was $5 \% \mathrm{v} / \mathrm{v}$ (Figure 3). The higher amount of CS in the formulation led to the faster disintegration of the tablets. No disintegration has been noticed in the tablets containing only PGS. The bigger particle size of PGS led to the significantly faster disintegration of the tablets formulation containing $0-90 \% \mathrm{CS}$ as presented in Figure $3 \mathrm{a}$ and Figure $3 \mathrm{~b}$.

\section{Tablet hardness}

Hardness is one of the important factors that have an effect on disintegration time of tablets. This study also investigated the effect of the amount of CS in the formulations on the hardness of the tablets. For the tablets containing MCC, the increase in CS amount from 2 to $10 \%$ in the formulations have an only small effect on the hardness of the tablets. Further increased the CS in the formulation (> $10 \%$ ) resulted in the decrease in hardness of the tablets. The small size MCC have more effect on the decrease in hardness as compared to the bigger size MCC does as shown in Figure 4. The significant difference in the hardness of the tablets containing small size and big size MCC was found at $0-5$ and $15-90 \%$ CS in the formulations.

In the case of the formulation containing DCP and CS, the hardness gradually increased with an increase in CS amount. The addition of CS more than $40 \%$ into the formulation led to the dramatic increase in the hardness. The hardness of the formulations containing small particle size DCP was significantly greater than that of the formulations containing big particle size DCP. However, when the formulations consisted of the high amount of CS (80-90\%), the hardness of the formulations containing big particle size DCP was significantly greater than that of the formulations containing small particle size DCP as presented in Figure 5. 

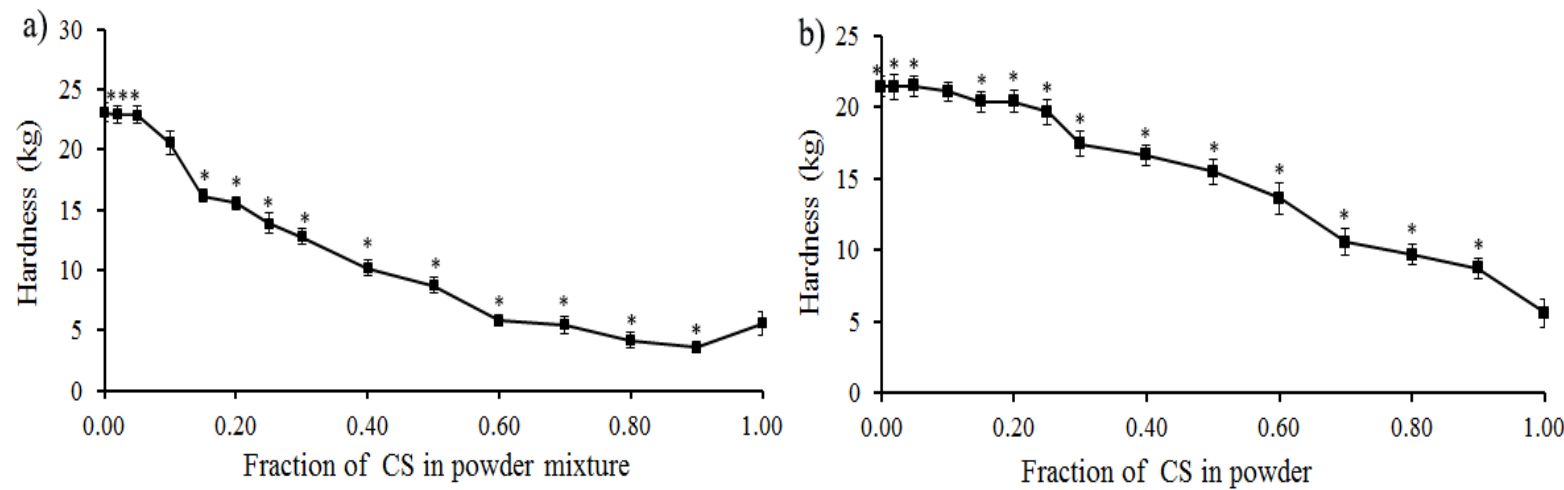

Figure 4: Relationship between the amount of CS in the binary mixture before tableting and the hardness of the tablets containing MCC: (a) small size MCC $(112.5 \mu \mathrm{m})(\mathrm{b})$ bigger size MCC $(215.0 \mu \mathrm{m})$. * Statistical difference in the hardness of tablets containing (a) small size MCC and (b) big size MCC at the similar CS ratio
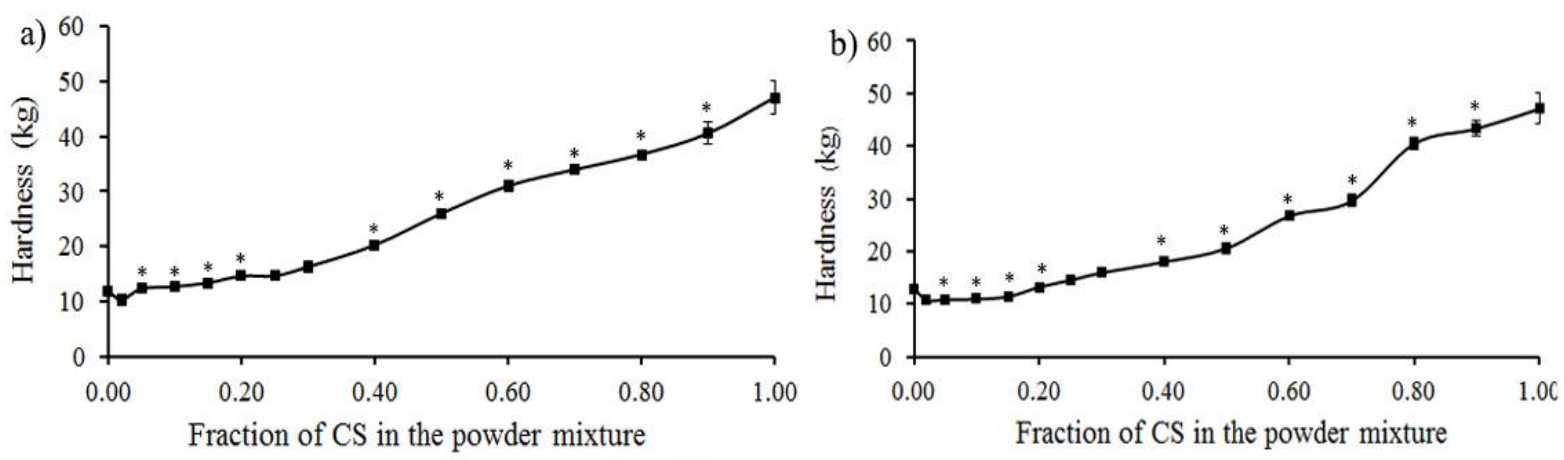

Figure 5: Relationship between the amount of CS in the binary mixture before tableting and the hardness of the tablets containing DCP: (a) small particle size DCP $(215.0 \mu \mathrm{m})$ (b) bigger size DCP (337.5 $\mu \mathrm{m})$. ${ }^{*}$ Statistical difference in the hardness of tablets containing (a) small size DCP and (b) big size DCP at the similar CS ratio
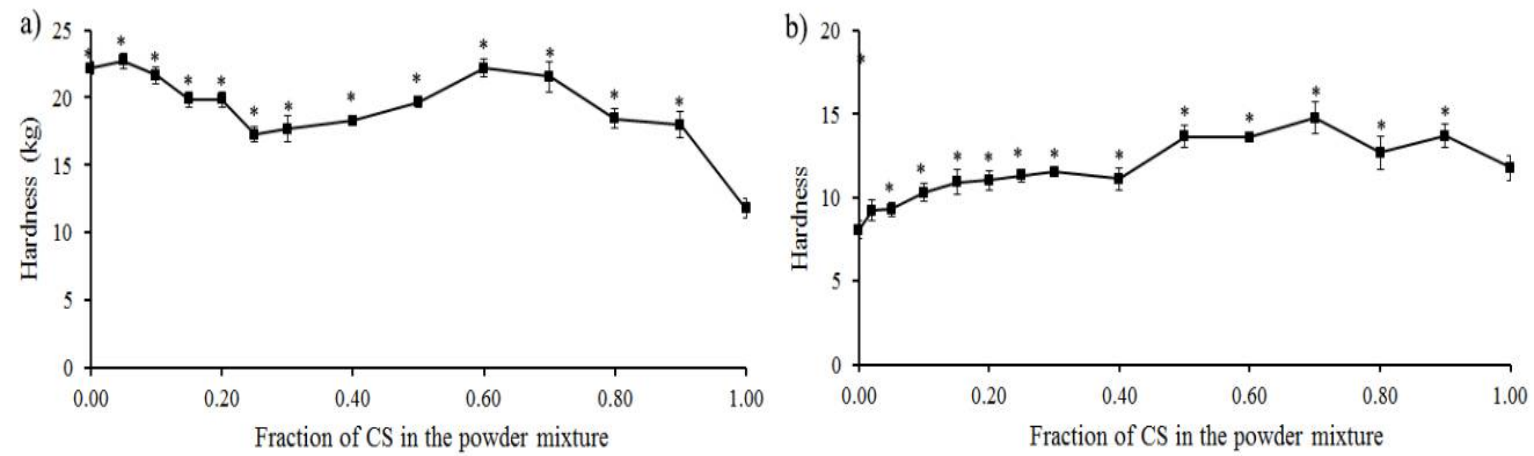

Figure 6: Relationship between the amount of CS in the binary mixture before tableting and the hardness of the tablets containing MCC: (a) small particle size PGS $(<112.5 \mu \mathrm{m})$ (b) larger particle size PGS $(112.5 \mu \mathrm{m})$. * Statistical difference in the hardness of tablets containing (a) small size PGS and (b) big size PGS at the similar CS ratio

On the other hand, in the formulation containing PGS and CS, increasing the amount of CS in the formulation caused a fluctuating change in the hardness. The hardness seemed to decrease after increased the amount of CS in the formulations containing small size PGS. However, in the formulation containing big size PGS, the hardness increased as the amount of $C S$ in the formulations increased. The tablets containing small size PGS exhibited significantly higher and more fluctuate hardness as compared to the formulations with big size PGS (Figure 6).

\section{DISCUSSION}

Percolation theory has been employed in pharmaceutical industry to improve tablet formulation and production processes. In order to design tablet formulations, the dissolution and disintegration of the tablets need to be taken into account. The disintegration of tablets remains an important issue for the desirable release of the active pharmaceutical ingredient from a solid dosage formulation [19]. It has been reported that heterogeneous mixtures like pharmaceutical formulations for solid dosage forms demonstrate 
disarranged particulate systems where it is necessary to consider a geometrical representation, in other words, a topological modeling $[17,20]$. Geometrical phase transitions are independent of physical and chemical properties of the components, which enable the modeling. Actually, percolation theory is the most suitable model to predict and simulate the geometrical phase transitions in a complex multiparticulate system $[21,22]$. As stated by percolation theory, a transitional change occurred at a critical concentration of components in a system when one component forms a cluster spreading throughout the whole system. This critical concentration, known as percolation threshold $(\mathrm{Cp})$, is assigned to the volumetric ratio $(\% \mathrm{v} / \mathrm{v})$ of the percolating component $[13,14]$.

In this study, CS was used as a disintegrant, and MCC, DCP and PGS were used as diluents. As a matter of fact, MCC represents the water-soluble diluents which can help in disintegration process and demonstrates plastic deformation. On the other hand, DCP stands for the water-insoluble diluents which demonstrate fragmentation deformation. In addition, PGS represents the diluents that have been modified to improve water solubility and displayed an elastic deformation. In the theoretical point of views, CS acts as the percolating component that was expected to penetrate through the diluent and form an infinite cluster network structure spreading in the particulate system. Increasing the amount of the CS in the mixture could lead to the destruction of the network structure of the diluents and generate the new network.

The results from the disintegration study of the tablet formulation containing CS revealed that just little amount of CS can improve the disintegration of the tablets. In the formulation of MCC and CS, or DCP and CS, the percolation threshold was similar and found to be very low as $2 \% \mathrm{v} / \mathrm{v}$ even through MCC and DCP are different in water solubility. In fact, CS is a superdisintegrant that can destroy the network structure of the diluent and reduce the attraction force between the diluent molecules resulted in the disintegration of the tablets. When the tablets contact with water, water will penetrate into the tablets. This can cause the CS to swell and lead to the disintegration of the tablets. In the case of PGS, the percolation threshold was found to be 5 $\% \mathrm{v} / \mathrm{v}$. This is because PGS formed gels after contacted with water and decelerate the penetration of water into the tablets. Therefore, a higher amount of the disintegrant is necessary to induce disintegration. The effect of diluent sizes on the disintegration properties was also investigated. The results showed that the size of the diluents has an effect on disintegration. The tablet formulations containing small particle size MCC demonstrated faster disintegration compared with the formulation containing large particle size MCC. This may be due to the swelling properties of MCC. The small size MCC could swell faster and results in the faster disintegration. In the formulation containing PGS and CS, bigger particle size of PGS led to the faster disintegration. This may be because the tablets prepared from bigger PGS could be more porous than those prepared from small size PGS. The small particle size PGS might fill in the space between particles and then hinders the water penetration into the tablets when contact with water.

As expected, when CS demonstrates elastic deformation, it would destroy the network structure of the diluent and generate the new network between CS and the diluent. This leads to the change in hardness of the tablets after increasing the amount of CS in the formulations. There are some differences in hardness in the formulation containing different diluents after increasing the amount of CS in the formulation. This may be due to the different in deformation property of the different diluents used.

\section{CONCLUSION}

The critical concentration for disintegration or percolation thresholds (Cp) is the amount of disintegrant used in the tablet formulation to obtain the minimum value of the disintegration time. The amount of CS used at $2 \% \mathrm{v} / \mathrm{v}$ is sufficient to initiate rapid disintegration of the tablets prepared from MCC and CS mixture as well as DCP/CS mixture. A greater amount of CS $(5 \%)$ is needed for the disintegration of the tablets prepared from PGS and CS mixture. The particle size of the diluents has an effect on the disintegration of the tablets.

\section{DECLARATIONS}

\section{Acknowledgement}

The authors would like to thank Faculty of Pharmacy, Silpakorn University for financial support, as well as Mr Pariwat Phadungart, Ms. Pattraporn Piumjareonsook and Ms. Patcharin Jaipukdee for research assistance.

\section{Conflict of Interest}

No conflict of interest associated with this work. 


\section{Contribution of Authors}

The authors declare that this work was done by the authors named in this article and all liabilities pertaining to claims relating to the content of this article will be borne by them.

\section{Open Access}

This is an Open Access article that uses a funding model which does not charge readers or their institutions for access and distributed under the terms of the Creative Commons Attribution License (http://creativecommons.org/licenses/by/ 4.0) and the Budapest Open Access Initiative (http://www.budapestopenaccessinitiative.org/rea d), which permit unrestricted use, distribution, and reproduction in any medium, provided the original work is properly credited.

\section{REFERENCES}

1. Ummadi S, Shravani B, Rao R, Reddy MS, Sanjeev BN. Overview on controlled release dosage form. Int $J$ Pharm Sci 2013; 3(4): 258-269.

2. Upadhyay $P$, Nayak K, Patel K, Patel J, Shah $S$, Deshpande J. Formulation development, optimization, and evaluation of sustained release tablet of valacyclovir hydrochloride by combined approach of floating and swelling for better gastric retention. Drug Deliv TransI Res 2014; 4(5-6): 452-64.

3. Dey P, Maiti S. Orodispersible tablets: $A$ new trend in drug delivery. J Nat Sc Biol Med 2010; 1(1): 2-5.

4. Sameer GL, Yi YY, Ajay KB. Effects of disintegrationpromoting agent, lubricants and moisture treatment on optimized fast disintegrating tablets. Int J Pharm 2009; 365(4-1): 4-17.

5. Samprasit $W$, Opanasopit $P$, Akkaramongkolporn $P$, Ngawhirunpat $T$, Wongsermsin $K$, Panomsuk $S$. Preparation and evaluation of taste-masked dextromethorphan oral disintegrating tablet. Pharm Dev Techno 2012; 17(3): 315-20.

6. Desai PM, Liew CV, Heng PWS. Review of Disintegrants and the Disintegration Phenomena. J Pharm Sci 2016; 105(9): 2545-2555.

7. Augsburger LL, Zellhofer MJ. Tablet formulation. In: Swarbrick J, ed. Encyclopedia of Pharmaceutical Technology. 3rd edn. New York, NY: Informa Healthcare USA, Inc; 2007: 3641-3652.

8. Moreton RC. Disintegrants in tableting. In: Augsburger LL, Hoag SW, eds. Pharmaceutical Dosage Forms: Tablets. 3rd edn. New York, NY: Informa Healthcare USA, Inc; 2008. p. 217-249.
9. Goncalves-Araujo T, Rajabi-Siahboomi AR, Caraballo I. Application of percolation theory in the study of an extended release Verapamil hydrochloride formulation. Int J Pharm 2008; 361(1-2): 112-117.

10. Fuertes I, Miranda A, Millan M, Caraballo I. Estimation of the percolation thresholds in acyclovir hydrophilic matrix tablets. Eur J Pharm Biopharm 2006; 64(3): 336-342.

11. Stauffer $D$, Aharony A. Introduction to percolation theory, 2nd ed., Washington DC: CRC Press. 1992. 192 p.

12. Leuenberger $H$, Rohera $B H$, Haas C. Percolation theory-a novel approach to solid dosage form design. Int J Pharm 1987; 38: 109-115.

13. Millán $M$, Caraballo I, Rabasco $A$. The role of the drug/excipient particle size ratio in the percolation model for tablets. Pharm Res 1998; 15(2): 220-224.

14. Goncalves-Araujo T, Rajabi-Siahboomi AR, Caraballo I. Polymer percolation threshold in HPMC extended release formulation of carbamazepine and verapamil HCl. AAPS PharmSciTech 2010; 11(2): 558-562.

15. Yuasa $H$, Kanaya $Y$. Studies on internal structure of tablets. II. Effect of the critical disintegrator amount on the internal structure of tablets. Chem Pharm Bull 1986; 34 (12): 5133-5139.

16. Commons KC, Bergen A, Walker GC. Influence of starch concentration on the disintegration time of tolbutamide tablets. J Pharm Sci 1968; 57 (7): 1253-1255.

17. Kimura G, Puchkov M, Betz G, Leuenberger $H$. Percolation Theory and the role of maize starch as a disintegrant for a low water-soluble drug, Pharm Dev Techno 2007; 12(1): 11-19.

18. Ferrari F, Bertoni M, Bonferoni CM, Rossi S, Caramella $C$, Bolhuis GK. Dissolution enhancement of an insoluble drug by physical mixture with a superdisintegrant: optimization with a simplex lattice design. Pharm Dev Technol 1996; 1(2): 159-164.

19. Rojas J, Guisao S, Ruge V. Functional assessment of four types of disintegrants and their effect on the spironolactone release properties. AAPS PharmSciTech 2012; 13(4): 1054-1062.

20. Ringard J, Guyot-Hermann AM. Calculation of disintegrant critical concentration in order to optimize tablets disintegration. Drug Dev Ind Pharm 1988; 14 : 2321-2339.

21. Leuenberger $H$, Rohera $B D$, Hass $C$. Percolation theory-A novel approach to solid dosage form design. Int J Pharm 1987; 38: 109-115.

22. Krausbauer E, Puchkov M, Betz G, Leuenberger $H$. Rational estimation of the optimum amount of nonfibrous disintegrant applying percolation theory for binary fast disintegrating formulation. J Pharm Sci 2008; 97(1): 529-541. 